Wahren - Das lernende Unternehmen 

Heinz-Kurt E. Wahren

Das lernende Unternehmen

Theorie und Praxis des

organisationalen Lernens

$\mathrm{W}$
$\mathrm{DE}$
$\mathrm{G}$

Walter de Gruyter - Berlin - New York 1996 
Heinz-Kurt E. Wahren, Dipl.-Betriebswirt

Geschäftsführer

ComConsult Unternehmensberatung $\mathrm{GmbH}$, Mögglingen

Lehrbeauftragter

- Fachhochschule Aalen

- Fachhochschule Schwäbisch Gmünd, Hochschule für Gestaltung

- Universität Augsburg

Mit 48 Abbildungen und Tabellen

Die Deutsche Bibliothek - CIP Einheitsaufnahme

Wahren, Heinz-Kurt E.:

Das lernende Unternehmen: Theorie und Praxis des organisationalen Lernens ;

[mit Tabellen] / Heinz-Kurt E. Wahren. -

Berlin, New York : de Gruyter, 1996

$\square$ ISBN 3-11-014790-4

(C) Copyright 1996 by Walter de Gruyter \& Co., 10785 Berlin

Dieses Werk einschließlich aller seiner Teile ist urheberrechtlich geschützt. Jede Verwertung außerhalb der engen Grenzen des Urheberrechtsgesetzes ist ohne Zustimmung des Verlages unzulässig und strafbar. Dies gilt insbesondere für Vervielfältigungen, Übersetzungen, Mikroverfilmungen und die Einspeicherung und Verarbeitung in elektronischen Systemen. Umschlagentwurf: Johannes Rother, Berlin - Druck: WB-Druck, Rieden - Bindearbeiten: Lüderitz \& Bauer, Berlin. - Printed in Germany. 


\section{Statt eines Vorworts}

... ein fiktives Gespräch zwischen Günter Dux, Walter Benjamin und Ludwig Wittgenstein:

Günter DUX: «Auch wenn es Sinn hat zu sagen, der Mensch könne nicht nicht lernen; damit er wirklich lernt, muß erst die gedeutete Welt unsicher werden, er selbst gezwungen sein, sich nach verläßlicherem Wissen umzusehen."

(Die Logik der Weltbilder, 1990: 275)

Walter BENJAMIN: Wenn dem so ist, dürfen wir uns wnicht scheuen, immer wieder auf einen und denselben Sachverhalt zurückzukommen; ihn auszustreuen wie man Erde ousstreut, ihn umzuwühlen wie man Erdreich umwühlt. Denn Sachverhalte sind nur Lagerungen, Schichten, die erst der sorgsamsten Durchforschung das ausliefern, was die wahren Werte, die im Erdinnern stecken, ausmacht: die Bilder, die aus allen früheren Zusammenhängen losgebrochen als Kostbarkeiten in den nüchternen Gemöchern unserer spöten Einsicht stehen .

(Berliner Chronik, 1986: 486)

Ludwig WITTGENSIEIN: In all diesem Bemühen sollte es jedoch unser Ziel sein, daß wir "der Fliege den Ausweg aus dem Fliegenglas zeigen ".

(Philosophische Untersuchungen, 1984: 378) 
